\title{
Review
}

\section{Clinical canine spinal cord injury provides an opportunity to examine the issues in translating laboratory techniques into practical therapy}

\author{
ND Jeffery*, ${ }^{*}$, PM Smith ${ }^{1}$, A Lakatos ${ }^{1}, \mathrm{C} \mathrm{Ibanez}^{1}$, D Ito ${ }^{1}$ and RJM Franklin ${ }^{1}$ \\ ${ }^{1}$ Department of Veterinary Medicine, University of Cambridge, Cambridge, UK
}

\begin{abstract}
Study design: Review.
Objectives: To highlight the value of investigating the effects of putative therapeutic interventions in clinical spinal cord injury (SCI) in domestic dogs.

Setting: England, UK.

Methods: Many experimental interventions in laboratory rodents have been shown to ameliorate the functional deficits caused by SCI; the challenge now is to determine whether they can be translated into useful clinical techniques. Important differences between clinical SCI in human patients and that in laboratory rodents are in the size of the spinal cord and heterogeneity of injury severity. A further key issue is whether the statistical difference in outcome in the laboratory will translate into a useful difference in clinical outcome. Here, we stress the value of investigating the effects of putative therapies in clinical SCI in domestic dogs. The causes of injury, ability to categorise the severity and methods available to measure outcome are very similar between canine and human patients. Furthermore, postmortem tissue more rapidly becomes available from dogs because of their short lifespan than from human patients.

Results: The role that investigation of canine SCI might play is illustrated by our preliminary trials on intraspinal transplantation of olfactory glial cells for severe SCI.

Conclusions: This canine translational model provides a means of 'filtering' putative treatments before human application.

Sponsorship: Our work described here was supported by the International Spinal Research Trust.

Spinal Cord (2006) 44, 584-593. doi:10.1038/sj.sc.3101912; published online 7 March 2006
\end{abstract}

Keywords: translational; intraspinal; transplantation; naturally occurring

\section{Introduction}

During the last two decades, a large number of interventions have been successful in improving the outcome after spinal cord injury (SCI) in experimental rodents. $^{1-5}$ These interventions can be subdivided into those that exert effects through putative neuroprotective, ${ }^{6}$ regenerative ${ }^{7-9}$ or plasticity-inducing ${ }^{10,11}$ mechanisms, many of which have been substantiated through further in vivo, or in vitro, experiments. However, although an intervention might show great promise by alleviating the effects of SCI in an experimental animal model, there are many differences between experimental SCI in rodent models and the clinical injuries that occur in human patients. The difficulty in making the transition between the lab and the clinic has also been experienced in potential treatments for stroke and

*Correspondence: ND Jeffery, Department of Veterinary Medicine, University of Cambridge, Madingley Road, Cambridge CB3 0ES, UK traumatic brain injury, ${ }^{12,13}$ in which many interventions found to be highly efficacious in rodent (or even primate) models fail in clinical trials in human patients.

Although there is a common assumption that a successful animal experiment presages successful clinical trials, it is crucial that unsustainable optimism is not widely disseminated since any therapeutic failures will inevitably lead to disillusionment among patients, scientists and the general public. The issue of pitfalls between lab and clinic is now becoming more pressing since cell transplant therapies for human SCI have now commenced in China and elsewhere, ${ }^{14-16}$ and may soon commence in many Western countries. ${ }^{17}$ The unhealthy cycle between hyperbole and disillusionment must be avoided if the public are to view scientists working in this field with trust. How might this best be avoided? Here, we highlight the case for using clinical SCI in dogs as an intermediate between rodent experiments and human clinical trials. 


\section{Steps in the transition from laboratory SCI models to human treatment}

\section{Experimental models of SCI}

Historically, the earliest attempts to model clinical SCI relied on 'weight drop' impact to the spinal $\operatorname{cord}^{18}$ and contusive injury models, through refinement, have remained popular since then, relying on mechanisms by which the exposed dorsal aspect of the spinal cord is impacted by a force of defined magnitude. ${ }^{19-21} \mathrm{An}$ alternative method is the temporary application of an aneurysm clip to the exposed spinal cord ${ }^{22}$ which although reliant on a compressive force, more closely models a contusive injury as the compression is only transient. This highly versatile model, in which the degree of injury can be reproducibly controlled by varying the duration of clip application, ${ }^{22}$ has also been extensively exploited, including use in mice ${ }^{23}$ and in vitro. ${ }^{24}$

However, there are many other experimental models of SCI and each has advantages and disadvantages in investigating various aspects of lesion development, recovery mechanisms and putative therapeutic interventions. Thus, complete spinal cord transection often provides the most unequivocal information regarding axonal regeneration, ${ }^{25-27}$ and spinal hemisection, or more localised sharp spinal injuries, provides invaluable data regarding plastic mechanisms of recovery of function. ${ }^{28,29}$ Similarly, attempts to understand the cellular and molecular events that follow clinical SCI are most reliant on contusion models (see above) that mimic the events that occur commonly in human SCI. Such models have allowed exploration of the underlying biochemical and cellular events that give rise to tissue destruction and have therefore suggested new targets for therapeutic intervention. ${ }^{30-33}$ Modelling of contusion has also proved useful because variations in the severity of injury can be correlated with functional outcome, ${ }^{34}$ allowing deductions to be made regarding the tissuesparing efficacy of putative therapeutic interventions.

\section{Differences between clinical and experimental injuries}

Despite the substantial gains in knowledge resulting from contusion models, there are many differences between contusive injury models and clinical injuries. First, most acute clinical spinal cord injuries consist of a mixture of contusion and persistent compression, because they result from sudden and persistent impingement of soft tissue (disc lesions) or bone (fractures or luxations) on the spinal cord, whereas the majority of experimental models are contusive only. A mixed compressive-contusive lesion can be mimicked in the laboratory, most conveniently by the use of inflatable balloons, ${ }^{35-37}$ or transvertebral screws. ${ }^{38,39}$ However, such models have rarely found long-term favour because variability in histological and functional outcome confounds the ability to detect the underlying cellular and molecular chain of events developing tissue damage or the effects of therapeutic agents.
Second, clinical injuries most frequently are caused by structures located ventral to the cord - the intervertebral disc or the vertebral bodies - whereas in experimental contusion, the impacting force is applied dorsally, meaning that the epicentre of the injury is located differently within the transverse area of the spinal cord (although, in severe injury this may not be a problem in terms of modelling since the whole cord will be damaged).

Lastly, there is the important issue of variability. In experimental lesions, there is a deliberate attempt to limit the variability in lesion severity and its precise intracord location to facilitate dissection of the effects of any intervention. Conversely, in clinical SCI, there is much variability regarding severity, type and precise location of the lesion. Clinical classification schemes (eg ASIA or Frankel scales; or white matter versus grey matter lesions) represent attempts to group together patients who are known to have specific prognoses, but will never reach the grouping accuracy that can be achieved by reproducible laboratory techniques. This inherent, and partially 'unknowable', variability is one source of apparent conflict between data derived from laboratory studies and those derived from translating interventions into clinical cases. ${ }^{40}$ Thus, the demonstration of a statistical difference in outcome between control rats and those treated with a putative therapeutic agent may not be reproduced in a relatively heterogenous human patient population. There may indeed be a beneficial effect, but its magnitude may be sufficiently small to become lost in the statistical 'noise' of the inherent variability in the patient population and demonstrates the difference between statistical significance and biological (or medical) relevance. Investigating this difference is a key role for translational research.

\section{Differences in size (the 'scaling up' question)}

From the point of view of neuroprotective drug interventions, the difference in size between a rodent and a human spinal cord is not of great importance - it is simply a matter of administering the correct dosage. For cell transplantation therapies - which will soon be trialled in human patients - the difference in size does raise some practical questions. Experimental severe SCI lesions in rats are spindle-shaped and $\sim 10 \mathrm{~mm}$ long with a maximum diameter of $\sim 3 \mathrm{~mm}$ - therefore the volume can be calculated crudely to be $\sim 35 \mathrm{~mm}^{3}$. In contrast, human spinal cord injuries can be at least $25 \mathrm{~mm}$ long with a diameter of $\sim 14 \mathrm{~mm}$, a calculated volume of $\sim 2500 \mathrm{~mm}^{3}$ (approximately 75 times larger than the rat lesion).

Although this difference could simply be viewed as requiring a 'dose' correction for the larger volume of lesion, there are more fundamental biological properties that may be involved. For instance, the migratory and proliferative capacity of the cells may be a limiting factor to adequate distribution throughout the lesioned tissue, as has been noted in studies on remyelination of 
large CNS lesions, ${ }^{41}$ whereas the relatively larger distances of cells from viable blood supply may render large portions of human SCI sites inhospitable to transplanted cells. For instance, some workers have shown considerable migration of transplanted (olfactory ensheathing) cells within the injured spinal cord, ${ }^{42}$ but this does not appear to occur universally, ${ }^{43,44}$ perhaps reflecting the sensitivity of the transplanted cells to subtle differences in lesion environment.

Similarly, certain interventions are associated with axonal regeneration in the spinal cord, such as inhibition of NOGO receptor signalling, ${ }^{45-47}$ neurotrophin administration, ${ }^{48,49}$ olfactory ensheathing cell (OEC) transplantation, ${ }^{26,42}$ or combinations of cells and neurotrophins. ${ }^{50,51}$ Regeneration over a distance of several millimetres in a rat may have a profound effect on function, whereas in a human patient, such regeneration may be insignificant (although this is highly dependent on the precise region of the cord).

In conclusion therefore, although a starting point would be to use a dose correction to determine the number of cells required for transplant in a large-sized cord, it cannot necessarily be assumed that this will be correct, meaning that further trials in intermediate models would be useful.

\section{Incidence and aetiology of canine SCI}

The precise incidence of canine SCI is uncertain because not all cases of spinal injury will receive veterinary attention and many affected cases will swiftly be euthanised before referral to veterinary spinal specialists. Nevertheless, SCI undoubtedly occurs commonly in dogs, for two main reasons: first, they are frequently the victims of road traffic accidents, owing to their lack of road sense and poor owner management, ${ }^{52}$ second, there is a high rate of disc degeneration (predominantly in smaller, chondrodystrophic types of $\operatorname{dog})^{53,54}$ that can lead to acute nuclear extrusions associated with a mixed contusive-compressive injury to the spinal cord (see Figure 1a). Therefore, the mechanisms of injury in clinical SCI in dogs are similar to those in human patients: vertebral fracture-luxation (Figures $1 \mathrm{~b}$ and c) and disc extrusions - both of which produce the mixed contusion-compression lesion to the ventral aspect of the cord that is problematical to model in the laboratory. Although both cervical and thoracolumbar (TL) SCI can occur following both types of incident, TL SCI is more common and provides a more convenient population for modelling human SCI as care of affected individuals is more straightforward.

The similarities between the type of cord injury induced by acute disc extrusions in dogs and fractureluxations in human patients have long attracted notice $^{5-57}$ and clinical canine SCI has been investigated for its potential as an intermediate model in several previous studies. ${ }^{58}$ Notably, investigators at Purdue University investigated the effects of 4-AP and electromagnetic stimulation on severely injured canine spinal cord, ${ }^{59,60}$ paving the way for human clinical trials; the
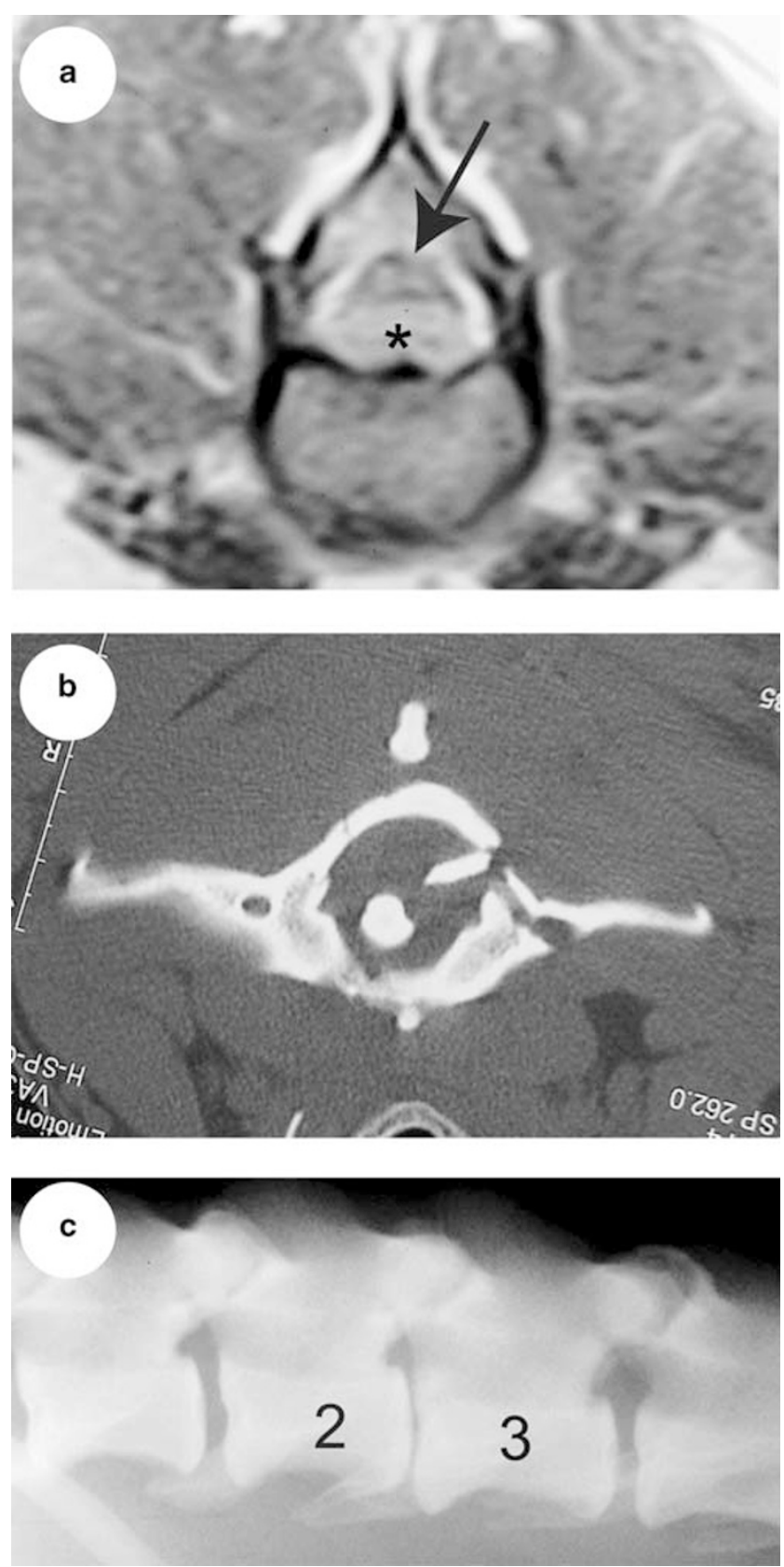

Figure 1 Mechanisms of injury to the canine spinal cord resemble those occurring in human patients. (a) On this T1W transverse MR scan, the nucleus of the intervertebral disc (IVD) can be seen to have extruded dorsally (*), causing compression of the spinal cord (arrowed). This process can occur explosively, causing a mixed compressive/contusive lesion. (b) A fractured portion of the atlas is impinging on the spinal cord (CT scan). (c) Narrowed intervertebral disc space and displaced vertebral canal associated with a fracture/ luxation between L2 and L3 vertebrae

recent publication of a study of the effects of intravenous PEG has reiterated the value of canine SCI in testing putative neuroprotective agents. ${ }^{61}$ In this review, we have focused specifically on the use of clinical SCI in dogs as a model in which to investigate the efficacy of 
intraspinal cell transplantation, which has hitherto not been explored.

\section{Pathology}

The gross and microscopic pathology of canine SCI lesions has been studied for many years in veterinary medicine $^{55}$ and is similar to that reported in experimental rodents and human patients. Thus, mild contusive-compressive lesions are associated with focal destruction of grey matter, whereas more severe lesions can lead to almost total destruction of the entire cross-section of the spinal cord. Many dogs that suffer severe SCI are euthanised and immediate perfusionfixation is possible; the ready availability of such tissue allows very detailed pathological analysis of clinical SCI, which is rarely possible in human patients (see Figure 2).

A particular benefit to examination of perfusion-fixed canine tissue is the opportunity for ultrastructural analysis of white matter damage after SCI, as the incidence and significance of demyelination has long been debated. ${ }^{62,63}$ In canine tissue, segmental demyelination following SCI appears to be relatively rare, and likely is a transient event as it is unusual at late time points (ie beyond three weeks after injury). This mirrors the findings in the available human tissue, in which substantial demyelination was only found in one of 22 examined cases. ${ }^{63}$ Similarly, Schwann cell invasion of the damaged spinal cord is uncommon in canine tissue, unless laceration of the meninges accompanies gross tissue destruction - again a finding that parallels those made in both rodent and human tissue. ${ }^{64}$

Although the observable cellular responses at the light microscopic level have been well documented, the local and systemic immune responses to SCI have been little studied in canine patients, in contrast to the rapid advances in this field made in rodent SCI. ${ }^{65}$ Therefore, the extent to which changes in immune status following canine SCI mimic those in rodents, or humans, is unclear at this time.

\section{Treatment and prognosis}

The functional sequelae of - and therapeutic options for - SCI in dogs are broadly similar to those in human patients: a large proportion of cases will respond adequately to conventional treatment by surgical decompression or conservative therapy. ${ }^{66,67}$ Thus, it is well recognised that there is substantial improvement in clinical signs in many human patients that suffer incomplete $\mathrm{SCI},{ }^{68-70}$ which can, indeed, complicate analysis of clinical trials of novel therapeutic interventions. $^{71,72}$ However, in common with human SCI patients, there is a subpopulation of affected dogs in which recovery is incomplete or does not occur at all; these affected dogs can be identified with reasonable certainty at an early stage after injury because they lose all sensory and motor function in the hindquarters and pelvic limbs. $^{73}$

\section{Predicting outcome}

Canine TL SCI patients with a good prognosis for recovery retain sensation to the pelvic limbs and have minimal regions of hyperintensity on T2W MRI scans. ${ }^{74}$ Conversely, the loss of pain sensation to the pelvic limbs is always associated with a worse prognosis: in association with fracture-luxations, it immediately indicates a very poor, or hopeless, prognosis; after disc extrusionrelated cord contusion-compression lesions, it indicates a poor to hopeless prognosis if still absent by $\sim 6$ weeks after the initiating incident. ${ }^{73}$ This is a patient population analogous to the population of human patients for which novel therapies would initially be targeted.

\section{Monitoring outcome}

Clinical scales of SCI injury severity have been established and widely used in dogs, ${ }^{75}$ they are similar to ASIA and Frankel scales used in human medicine, allowing close analogies to be made in clinical outcome scores between the species. In addition, normal values for sensory and transcranial magnetic motor-evoked potentials have been established in dogs ${ }^{76-79}$ although not in routine clinical use.

Domestic dogs are generally highly amenable to training and functional testing and this feature permits future subtle analysis of their recovery after SCI. Although routine clinical assessment of canine SCI relies on relatively broad categories of severity, ${ }^{75}$ it is possible to apply similar scoring schemes in dogs as have been applied to laboratory rodents. ${ }^{80}$ Many of the functional tests available to define the outcome after SCI in experimental animals have the potential to be adapted for use in dogs, ${ }^{81}$ although more sophisticated methods of analysis may also be required for future comparisons of transplanted and nontransplanted cases. Analysis of autonomic function after SCI in dogs has been comparatively neglected, although the overall control mechanisms for urinary continence are very similar to those in humans, ${ }^{82}$ and mismatching of bladder and urethral tone is a sufficiently well-recognised consequence of canine TL SCI that dogs are used for modelling continence disorders after SCI. ${ }^{83}$ Owing to the similarities, urinary continence in particular is amenable to analysis by methods in routine use in human patients. ${ }^{84}$

\section{Comparison with other intermediate models}

The evident conclusion is that clinical SCI in dogs provides a model that is comparable in terms of mechanisms of injury, pathology, outcome, classification and functional monitoring to human SCI. In comparison with experimental injuries in rats, SCI in dogs provide the added variability that will be encountered in human patients, but are amenable to sophisticated postinterventional analysis. Compared to analysis of trials in human patients, dogs have the advantage that there is less of an ethical dilemma, as dogs do not suffer the addition of psychological stress associated 

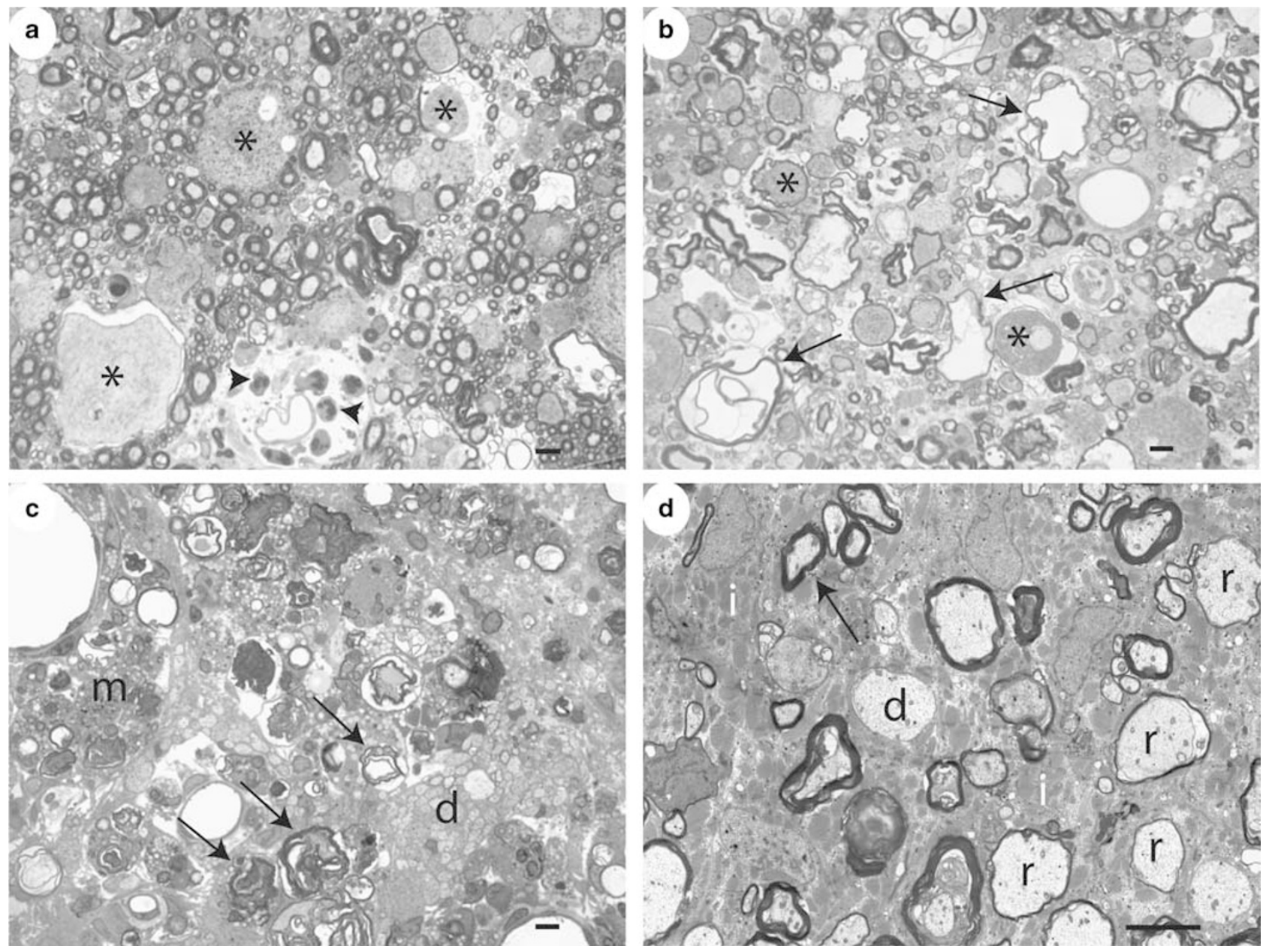

Figure 2 Perfusion-fixation permits high-quality pathological preparation in dogs that have sustained severe spinal cord injury. In each, animal tissue was prepared by perfusion using $4 \%$ gluteraldehyde, followed by routine dehydration and resin embedding. Tissue shown in $(\mathbf{a}-\mathbf{c})$ is taken from dogs that had lost all motor and sensory function to the pelvic limbs, that in (d) is taken from a dog that remained nonambulatory after an acute compressive lesion. (a-c) Toluidine blue stained $1 \mu \mathrm{m}$ sections; (d) electron micrograph. Scale bar (a-d) $5 \mu \mathrm{m}$. (a) After $48 \mathrm{~h}$, fracture/subluxation at L1/2: although many axons are of normal size and are invested by normal appearing myelin sheaths, many others are grossly swollen $(*)$. At this early stage, polymorphonuclear leucocytes are visible within the perivascular space (arrowheads). (b) $48 \mathrm{~h}$ : in another field, there is severe white matter destruction - the field is relatively acellular and contains few normal axons. There are many swollen axons (*) and widespread myelin 'figures', where myelin sheaths have become unravelled (arrows). (c) At 17 days after subluxation at T13/L1: some disrupted myelin still remains, much of it contained within macrophages (arrows) and there are many debris-filled macrophages in the perivascular space (m). A large number of axons are demyelinated (d). (d) At 12 weeks after the onset of severe disc-related compression at L1/2: many axons are remyelinated (r) at this chronic stage, although occasional demyelinated axons (d) are still apparent. The large spaces between axons are filled by astrocytic processes containing numerous intermediate filaments (i). A normal appearing axon is labelled (arrow) for comparison of myelin sheath thickness

with failed interventions and the relatively short lifespan means that histological analysis of outcome will be available much more quickly.

As dogs are quadrupeds and have less motor dominance by the pyramidal (corticospinal) tract, it might be argued that they are not suited for modelling human SCI. This is an aspect of human SCI for which it is it is difficult to use dogs and so a strong case can be made for the use of primates for this type of assessment. However, there is evidence that injury to the CST affects fine control of gait in other quadrupeds, including cats ${ }^{85}$ and mice ${ }^{86}$ indeed, the similarity in gait control mechanisms between quadrupeds and humans has previously been noted. ${ }^{87}$ Furthermore, the corticospinal tract is not the only pathway to be targeted for repair; for instance, incontinence and sexual dysfunction result in considerable loss of quality of life in human paraplegic patients. ${ }^{88,89}$ Such arguments strongly promote the view that investigation through several models provides complementary strands of information: thus, dogs can provide the missing variability associated with clinical SCI, whereas laboratory primates can be used to determine whether specific interventions are able to preserve, or regenerate, the corticospinal tract and its functions. 
In view of its strong clinical relevance, an important potential of canine SCI is to provide a screening test through which putative therapies can be examined, which may determine the need for further preclinical or human clinical trials. Thus, a technique that has proved successful in rats may not work in clinical cases in dogs, providing a strong argument for not progressing to human trials. On the other hand, a successful trial in dogs might suggest progress to primate or human clinical trials should be accelerated, and in which evidence of improved corticospinal tract function may be examined in detail.

\section{Practicalities of transition of OEC transplantation therapies from laboratory to clinic}

There are many practical issues to be addressed in translating cell transplantation therapy from the lab to the hospital, for instance there are questions regarding, inter alia, the optimal source of cells, how to culture them, how to place them in the lesion and how to monitor outcome. The availability of a clinically affected dog population allows these issues to be examined systematically before human trials, and is especially relevant because (a) the relatively large size of the spinal cord permits trials of various alternative neurosurgical techniques (particularly for transplantation) and, (b) the issue of cell source must be confronted and solved. Here, we describe the central practical issues in translation and outline how this practical problem solving may have relevance to human clinical trials.

\section{Patient selection}

The most obvious initial patients in which to trial a new therapy for SCI are those judged to have no hope of recovery by using conventional treatment. There are advantages and disadvantages to this selection. Even patients who have very severe SCI will still be able to demonstrate allodynia, which is the most feared complication of cellular transplantation into the spinal cord ${ }^{90}$ However, this group of patients is limited in its ability to express other potential deleterious effects of intraspinal transplantation, for instance on locomotion, as their predicted recovery is so limited anyway.

Conversely, the initial choice of very severely affected patients is likely to produce a parsimonious indication of any benefit as they are inherently much less likely to recover. Therefore, if initial studies demonstrate no detrimental effects of the intervention, future investigations would be better focused on groups of patients in which recovery of locomotion occurs in $\sim 50 \%$ of individuals, since this would allow determination of whether the intervention is capable of tipping the balance towards functional success (or failure). Fortunately, there is an easily identifiable group of such patients within the population of spinal cord injured dogs; $\sim 50 \%$ of those that suffer acute SCI as a result of extrusion of an intervertebral disc and lose all motor and sensory function to the pelvic limbs will recover the ability to walk. ${ }^{73,74,91}$
There will always be variability in the recovery rate after clinical SCI, owing to variability in the nature of the injury - even within defined severity groups - meaning that power calculations are required to optimise the experimental design. Depending on the study population, widely varying numbers of dogs might be required. ${ }^{58}$ However, by using animals that have reached a plateau of unacceptable recovery at 3 months (as defined above), a $10 \%$ difference in recovery between control and treated animals could be detected with a power of 0.8 using as few as 30 dogs per group. ${ }^{92}$ On assuming a spontaneous $50 \%$ recovery after loss of 'deep pain perception' following acute intervertebral disc extrusion, a $20 \%$ difference in proportion of recovering animals could be detected with a power of 0.8 with 60 dogs in each group. Bearing in mind the high incidence of SCI in dogs, both these group sizes can readily be attained.

\section{Cell sources}

Any potential cell transplantation therapy must address the question of where to obtain the cells. An advantage of nonautologous cells (allografting) is that there is usually, and in the case of OEC, invariably, a plentiful supply of tissue from which the cells can be derived. One drawback is that there can be ethical issues regarding the harvesting of appropriate tissue. In human patients, harvesting foetal tissue is highly emotive and might well prove an insuperable barrier to widespread adoption of this type of cell transplantation therapy in the West. On the other hand, harvesting cells from dead adult donors may not present such a problem. A drawback to the use of adult allograft cells is that they are likely to be immunogenic and elicit a rejection response - not only destroying the cells but also causing further tissue injury - unless immunosuppressive drugs are also administered. Such drugs are not without side effects ${ }^{93}$ and may vary in their ability to prevent rejection in different patient-transplant interactions, thereby introducing another source of variability in the assessment of outcome. Autologous sources are therefore preferable.

There are two main sources of autologous OEC: first, the olfactory bulb (OB), which is commonly used for obtaining cells from rodents $\mathrm{s}^{26,42,94,95}$ and second, the lamina propria of the olfactory mucosa ${ }^{96,97}$ In dogs, the $\mathrm{OB}$ is very prominent and easily accessed via a craniotomy incision; furthermore, it has the advantage of being sterile when obtained, whereas the olfactory mucosa could conceivably contain pathogens detrimental to cell viability or host tissue survival, although these potential difficulties can be overcome by stringent pretransplantation laboratory tests. ${ }^{98}$ Like those of rat and humans, canine OEC can be readily grown in vitro ${ }^{99}$ and sufficient numbers for transplantation (by extrapolation from successful rodent experiments) can be generated within 3 weeks in vitro culture time. ${ }^{100}$

\section{Transplantation procedure}

There are several possible methods of introducing cells into the spinal cord. In rodent experiments, OEC 
suspended in transport medium have been injected into the site of the lesion within the CNS, ${ }^{42}$ into the cut ends of spinal cord, ${ }^{26}$ and, in chronic cord injury, small fragments of olfactory mucosa have been implanted directly into the injury site. ${ }^{96}$ In chronic SCI, there is a glial scar, containing many well-defined molecular constituents that may be detrimental to transplanted cell migration and integration. ${ }^{101}$ Even so, OEC may have advantages over other cell types in this regard by being less responsive to inhibitory factors within the scar; indeed, there is evidence that they are able to beneficially modify its properties. ${ }^{96,102}$

As it has been suggested that support and direction of axon regeneration are prominent mechanisms by which transplanted OEC might ameliorate the functional loss caused by SCI, ${ }^{103}$ the transplantation method must ensure that they provide a bridge through the centre of the lesion and integrate with normal cord tissue at each end. This could be achieved by several means, two of which have been used in recent preliminary clinical trials: (i) multiple injections into the lesioned cord, which was preferred for a study on human patients, ${ }^{98}$ or (ii) using a myelotomy incision to divide the glial scar before injecting cells into the central deficit and both sides to infiltrate the whole region, which was used in a trial in dogs. ${ }^{100}$ There are, at present, no data to determine which of the possible techniques is preferable, demonstrating the need for further laboratory animal investigations and supporting the notion that a constant dialogue between lab and clinic is essential for continued progress.

\section{Future applications of the canine SCI model}

There is a constant stream of laboratory experiments suggesting new options for future treatment of SCI and these will each require evaluation for possible human application. The establishment of the canine model as an intermediate between rat and human interventions would aid and speed this transition by allowing screening of such diverse therapeutic possibilities as stem cell transplants, ${ }^{104}$ chondroitin $\mathrm{ABC},{ }^{105}$ rolipram $^{106}$ or combination therapy, and has recently shown its potential in the successful canine clinical trial of intravenous PEG. ${ }^{58}$

\section{Acknowledgements}

This work was supported by a grant from the International Spinal Research Trust.

\section{References}

1 Curt A, Schwab ME, Dietz V. Providing the clinical basis for new interventional therapies: refined diagnosis and assessment of recovery after spinal cord injury. Spinal Cord 2004; 42: 1-6.

2 Jeffery ND, Blakemore WF. Spinal cord injury in small animals 2. Current and future options for therapy. Vet Rec 1999; 145: 183-190.
3 Kleitman N. Keeping promises: translating basic research into new spinal cord injury therapies. J Spinal Cord Med 2004; 27: 311-318.

4 Ramer LM, Ramer MS, Steeves JD. Setting the stage for functional repair of spinal cord injuries: a cast of thousands. Spinal Cord 2005; 43: 134-161.

5 Tsai EC, Tator $\mathrm{CH}$. Neuroprotection and regeneration strategies for spinal cord repair. Curr Pharm Des 2005; 11: 1211-1222.

6 Kwon BK, Tetzlaff W, Grauer JN, Beiner J, Vaccaro AR. Pathophysiology and pharmacologic treatment of acute spinal cord injury. Spine J 2004; 4: 451-464.

7 Bunge MB. Bridging areas of injury in the spinal cord. Neuroscientist 2001; 7: 325-339.

8 Hendriks WT, Ruitenberg MJ, Blits B, Boer GJ, Verhaagen J. Viral vector-mediated gene transfer of neurotrophins to promote regeneration of the injured spinal cord. Prog Brain Res 2004; 146: 451-476.

9 Pearse DD et al. cAMP and Schwann cells promote axonal growth and functional recovery after spinal cord injury. Nat Med 2004; 10: 610-616.

10 Reier PJ. Cellular transplantation strategies for spinal cord injury and translational neurobiology. Neurorx 2004; 1: 424-451.

11 Schwab ME. Increasing plasticity and functional recovery of the lesioned spinal cord. Prog Brain Res 2002; 137: 351-359.

12 Gomes JA, Stevens RD, Lewin III JJ, Mirski MA, Bhardwaj A. Glucocorticoid therapy in neurologic critical care. Crit Care Med 2005; 33: 1214-1224.

13 Narayan RK et al. Clinical trials in head injury. J Neurotrauma 2002; 19: 503-557.

14 Boyd JG, Doucette R, Kawaja MD. Defining the role of olfactory ensheathing cells in facilitating axon remyelination following damage to the spinal cord. FASEB J 2005; 19: 694-703.

15 Huang $\mathrm{H}$ et al. Influence of patients' age on functional recovery after transplantation of olfactory ensheathing cells into injured spinal cord injury. Chin Med J (England) 2003; 116: 1488-1491.

16 Rabinovich SS et al. Transplantation treatment of spinal cord injury patients. Biomed Pharmacother 2003; 57: 428-433.

17 Senior K. Olfactory ensheathing cells to be used in spinalcord repair trial. Lancet Neurol 2002; 1: 269.

18 Allen AR. Surgery of experimental lesion of spinal cord equivalent to crush injury of fracture dislocation of spinal column. A preliminary report. J Am Med Assoc 1911; 57: 878-880.

19 Stokes BT, Jakeman LB. Experimental modelling of human spinal cord injury: a model that crosses the species barrier and mimics the spectrum of human cytopathology. Spinal Cord 2002; 40: 101-109.

20 Wrathall JR. Spinal cord injury models. J Neurotrauma 1992; 9(Suppl 1): S129-S134.

21 Young W. Spinal cord contusion models. Prog Brain Res 2002; 137: 231-255.

22 Rivlin AS, Tator CH. Effect of duration of acute spinal cord compression in a new acute cord injury model in the rat. Surg Neurol 1978; 10: 38-43.

23 Wells JE, Hurlbert RJ, Fehlings MG, Yong VW. Neuroprotection by minocycline facilitates significant recovery from spinal cord injury in mice. Brain 2003; 126: $1628-1637$.

24 Fehlings MG, Nashmi R. A new model of acute compressive spinal cord injury in vitro. $J$ Neurosci Methods 1997; 71: 215-224. 
25 Bregman BS et al. Transplants and neurotrophic factors increase regeneration and recovery of function after spinal cord injury. Prog Brain Res 2002; 137: 257-273.

26 Ramon-Cueto A, Cordero MI, Santos-Benito FF, Avila J. Functional recovery of paraplegic rats and motor axon regeneration in their spinal cords by olfactory ensheathing glia. Neuron 2000; 25: 425-435.

27 Fouad K, Schnell L, Bunge MB, Schwab ME, Liebscher T, Pearse DD. Combining Schwann cell bridges and olfactory-ensheathing glia grafts with chondroitinase promotes locomotor recovery after complete transection of the spinal cord. J Neurosci 2005; 25: 1169-1178.

28 Bareyre FM, Kerschensteiner M, Raineteau O, Mettenleiter TC, Weinmann O, Schwab ME. The injured spinal cord spontaneously forms a new intraspinal circuit in adult rats. Nat Neurosci 2004; 7: 269-277.

29 Diener PS, Bregman BS. Fetal spinal cord transplants support growth of supraspinal and segmental projections after cervical spinal cord hemisection in the neonatal rat. J Neurosci 1998; 18: 779-793.

30 Hauben E et al. Vaccination with dendritic cells pulsed with peptides of myelin basic protein promotes functional recovery from spinal cord injury. J Neurosci 2003; 23: 8808-8819.

31 Jones TB et al. Passive or active immunization with myelin basic protein impairs neurological function and exacerbates neuropathology after spinal cord injury in rats. J Neurosci 2004; 24: 3752-3761.

32 Teng YD, Wrathall JR. Local blockade of sodium channels by tetrodotoxin ameliorates tissue loss and long-term functional deficits resulting from experimental spinal cord injury. J Neurosci 1997; 17: 4359-4366.

33 Wrathall JR, Teng YD, Choiniere D. Amelioration of functional deficits from spinal cord trauma with systemically administered NBQX, an antagonist of non- $N$ methyl-D-aspartate receptors. Exp Neurol 1996; 137: 119-126.

34 Noble LJ, Wrathall JR. Correlative analyses of lesion development and functional status after graded spinal cord contusive injuries in the rat. Exp Neurol 1989; 103: $34-40$.

35 Martin D et al. Experimental acute traumatic injury of the adult rat spinal cord by a subdural inflatable balloon: methodology, behavioral analysis, and histopathology. J Neurosci Res 1992; 32: 539-550.

36 Vanicky I, Urdzikova L, Saganova K, Cizkova D, Galik J. A simple and reproducible model of spinal cord injury induced by epidural balloon inflation in the rat. J Neurotrauma 2001; 18: 1399-1407.

37 Fukuda $\mathrm{S}$ et al. New canine spinal cord injury model free from laminectomy. Brain Res Brain Res Protoc 2005; 14: 171-180.

38 Hashimoto T, Fukuda N. New spinal cord injury model produced by spinal cord compression in the rat. J Pharmacol Methods 1990; 23: 203-212.

39 al-Mefty $\mathrm{O}$ et al. Experimental chronic compressive cervical myelopathy. J Neurosurg 1993; 79: 550-561.

40 Maas AI. Neuroprotective agents in traumatic brain injury. Expert Opin Investig Drugs 2001; 10: 753-767.

41 Blakemore WF, Chari DM, Gilson JM, Crang AJ. Modelling large areas of demyelination in the rat reveals the potential and possible limitations of transplanted glial cells for remyelination in the CNS. Glia 2002; 38: 155-168.

42 Li Y, Field PM, Raisman G. Regeneration of adult rat corticospinal axons induced by transplanted olfactory ensheathing cells. J Neurosci 1998; 18: 10514-10524.
43 Barakat DJ et al. Survival, integration, and axon growth support of glia transplanted into the chronically contused spinal cord. Cell Transplant 2005; 14: 225-240.

44 Ramer LM, Au E, Richter MW, Liu J, Tetzlaff W, Roskams AJ. Peripheral olfactory ensheathing cells reduce scar and cavity formation and promote regeneration after spinal cord injury. J Comp Neurol 2004; 473: $1-15$.

45 Brosamle C, Huber AB, Fiedler M, Skerra A, Schwab ME. Regeneration of lesioned corticospinal tract fibers in the adult rat induced by a recombinant, humanized IN-1 antibody fragment. $J$ Neurosci 2000; 20: 8061-8068.

$46 \mathrm{Li} \mathrm{S}$ et al. Blockade of Nogo-66, myelin-associated glycoprotein, and oligodendrocyte myelin glycoprotein by soluble Nogo-66 receptor promotes axonal sprouting and recovery after spinal injury. $J$ Neurosci 2004; 24: 10511-10520.

47 GrandPre T, Li S, Strittmatter SM. Nogo-66 receptor antagonist peptide promotes axonal regeneration. Nature 2002; 417: 547-551.

48 Namiki J, Kojima A, Tator CH. Effect of brain-derived neurotrophic factor, nerve growth factor, and neurotrophin-3 on functional recovery and regeneration after spinal cord injury in adult rats. $J$ Neurotrauma 2000; 17: 1219-1231.

49 Bradbury EJ, Khemani S, King VR, Priestley JV, McMahon SB. NT-3 promotes growth of lesioned adult rat sensory axons ascending in the dorsal columns of the spinal cord. Eur J Neurosci 1999; 11: 3873-3883.

50 Cao Q et al. Functional recovery in traumatic spinal cord injury after transplantation of multineurotrophin-expressing glial-restricted precursor cells. J Neurosci 2005; 25: 6947-6957.

51 Ruitenberg MJ, Levison DB, Lee SV, Verhaagen J, Harvey AR, Plant GW. NT-3 expression from engineered olfactory ensheathing glia promotes spinal sparing and regeneration. Brain 2005; 128: 839-853.

52 Kolata RJ, Johnston DE. Motor vehicle accidents in urban dogs: a study of 600 cases. J Am Vet Med Assoc 1975; 167: 938-941.

53 Goggin JE, Li AS, Franti CE. Canine intervertebral disk disease: characterization by age, sex, breed, and anatomic site of involvement. Am J Vet Res 1970; 31: 1687-1692.

54 Hoerlein BF. Intervertebral discs. In: Hoerlein BF (ed). Canine Neurology. 3rd Edn, Chapter 14. WB Saunders: Philadelphia 1978, pp 470-560.

55 Griffiths IR. Spinal cord injuries: a pathological study of naturally occurring lesions in the dog and cat. J Comp Pathol 1978; 88: 303-315.

56 Griffiths IR. Some aspects of the pathology and pathogenesis of the myelopathy caused by disc protrusions in the dog. J Neurol Neurosurg Psychiatry 1972; 35: 403-413.

57 Hoerlein BF. Intervertebral disc disease. In: Oliver Jr JE, Hoerlein BF, Mayhew IG (eds). Veterinary Neurology. WB Saunders: Philadelphia 1987, p 328.

58 Olby N, Harris T, Burr J, Munana K, Sharp N, Keene B. Recovery of pelvic limb function in dogs following acute intervertebral disc herniations. J Neurotrauma 2004; 21: 49-59.

59 Blight AR, Toombs JP, Bauer MS, Widmer WR. The effects of 4-aminopyridine on neurological deficits in chronic cases of traumatic spinal cord injury in dogs: a phase I clinical trial. J Neurotrauma 1991; 8: 103-119.

60 Borgens RB et al. An imposed oscillating electrical field improves the recovery of function in neurologically 
complete paraplegic dogs. J Neurotrauma 1999; 16: 639-657.

61 Laverty PH et al. A preliminary study of intravenous surfactants in paraplegic dogs: polymer therapy in canine clinical SCI. J Neurotrauma 2004; 21: 1767-1777.

62 Waxman SG. Demyelination in spinal cord injury. J Neurol Sci 1989; 91: 1-14.

63 Bunge RP, Puckett WR, Becerra JL, Marcillo A, Quencer RM. Observations on the pathology of human spinal cord injury. A review and classification of 22 new cases with details from a case of chronic cord compression with extensive focal demyelination. Adv Neurol 1993; 59: 75-89.

64 Guest JD, Hiester ED, Bunge RP. Demyelination and Schwann cell responses adjacent to injury epicenter cavities following chronic human spinal cord injury. Exp Neurol 2005; 192: 384-393.

65 Jones TB, McDaniel EE, Popovich PG. Inflammatorymediated injury and repair in the traumatically injured spinal cord. Curr Pharm Des 2005; 11: 1223-1236.

66 Selcer RR, Bubb WJ, Walker TL. Management of vertebral column fractures in dogs and cats: 211 cases (1977-1985). J Am Vet Med Assoc 1991; 198: 1965-1968.

67 Coates JR. Intervertebral disk disease. Vet Clin North Am Small Anim Pract 2000; 30: 77-110.

68 Catz A, Goldin D, Fishel B, Ronen J, Bluvshtein V, Gelernter I. Recovery of neurologic function following nontraumatic spinal cord lesions in Israel. Spine 2004; 29: 2278-2282.

69 Scivoletto G, Morganti B, Ditunno P, Ditunno JF, Molinari M. Effects on age on spinal cord lesion patients' rehabilitation. Spinal Cord 2003; 41: 457-464.

70 Little JW, Ditunno Jr JF, Stiens SA, Harris RM. Incomplete spinal cord injury: neuronal mechanisms of motor recovery and hyperreflexia. Arch Phys Med Rehabil 1999; 80: 587-599.

71 Bracken MB et al. A randomized, controlled trial of methylprednisolone or naloxone in the treatment of acute spinal-cord injury. Results of the second national acute spinal cord injury study. $N$ Engl J Med 1990; 322: 1405-1411.

72 Coleman WP et al. A critical appraisal of the reporting of the national acute spinal cord injury studies (II and III) of methylprednisolone in acute spinal cord injury. $J$ Spinal Disord 2000; 13: 185-199.

73 Olby N, Levine J, Harris T, Munana K, Skeen T, Sharp $\mathrm{N}$. Long-term functional outcome of dogs with severe injuries of the thoracolumbar spinal cord: 87 cases (19962001). J Am Vet Med Assoc 2003; 222: 762-769.

74 Ito $\mathrm{D}$ et al. Magnetic resonance imaging as a prognostic indicator in dogs with paraplegia caused by thoracolumbar intervertebral disk herniation: 77 cases (2000-2003). $J$ Am Vet Med Assoc 2005; 227: 1454-1460.

75 Toombs JP, Waters DJ. Intervertebral disc disease. In: Slatter D (ed). Textbook of Small Animal Surgery. 3rd edn. WB Saunders: Philadelphia 2003, pp 1193-1209.

76 Kornegay JN, Marshall AE, Purinton PT, Oliver Jr JE. Somatosensory-evoked potential in clinically normal dogs. Am J Vet Res 1981; 42: 70-73.

77 Sylvestre AM, Cockshutt JR, Parent JM, Brooke JD, Holmberg DL, Partlow GD. Magnetic motor evoked potentials for assessing spinal cord integrity in dogs with intervertebral disc disease. Vet Surg 1993; 22: 5-10.

78 Vanderzant CW, Schott RJ, Natale JE, Pondo CA, D'Alecy LG. Somatosensory evoked potentials of the dog: recording techniques and normal values. $J$ Neurosci Methods 1989; 27: 253-263.

79 Poncelet L, Michaux C, Balligand M. Somatosensory potentials in dogs with naturally acquired thoracolumbar spinal cord disease. Am J Vet Res 1993; 54: 1935-1941.

80 Olby NJ et al. Development of a functional scoring system in dogs with acute spinal cord injuries. Am J Vet Res 2001; 62: 1624-1628.

81 Webb AA, Jeffery ND, Olby NJ, Muir GD. Behavioural analysis of the efficacy of treatments for injuries to the spinal cord in animals. Vet Rec 2004; 155: 225-230.

82 Lane IF. Diagnosis and management of urinary retention. Vet Clin N Am 2000; 30: 25-57.

83 Abdel-Gawad M, Boyer S, Sawan M, Elhilali MM. Reduction of bladder outlet resistance by selective stimulation of the ventral sacral root using high frequency blockade: a chronic study in spinal cord transected dogs. J Urol 2001; 166: 728-733.

84 Gregory SP, Holt PE. Comparison of stressed simultaneous urethral pressure profiles between anesthetized continent and incontinent bitches with urethral sphincter mechanism incompetence. Am J Vet Res 1993; 54: 216-222.

85 Drew T, Jiang W, Widajewicz W. Contributions of the motor cortex to the control of the hindlimbs during locomotion in the cat. Brain Res Brain Res Rev 2002; 40: 178-191.

86 Starkey ML et al. Assessing behavioural function following a pyramidotomy lesion of the corticospinal tract in adult mice. Exp Neurol 2005; 195: 524-539.

87 Dietz V. Do human bipeds use quadrupedal coordination? Trends Neurosci 2002; 25: 462-467.

88 Westgren N, Levi R. Quality of life and traumatic spinal cord injury. Arch Phys Med Rehabil 1998; 79: 1433-1439.

89 Anderson KD. Targeting recovery: priorities of the spinal cord-injured population. J Neurotrauma 2004; 21: 1371-1383.

90 Hofstetter CP et al. Allodynia limits the usefulness of intraspinal neural stem cell grafts; directed differentiation improves outcome. Nat Neurosci 2005; 8: 346-353.

91 Scott HW, McKee WM. Laminectomy for 34 dogs with thoracolumbar intervertebral disc disease and loss of deep pain perception. J Small Anim Pract 1999; 40: 417-422.

92 Jones SR, Carley S, Harrison M. An introduction to power and sample size estimation. Emerg Med J 2003; 20: 453-458.

93 Hathaway D, Winsett R, Prendergast M, Subaiya I. The first report from the patient outcomes registry for transplant effects on life (PORTEL): differences in sideeffects and quality of life by organ type, time since transplant and immunosuppressive regimens. Clin Transplant 2003; 17: 183-194.

94 Barnett SC, Roskams AJ. Olfactory ensheathing cells. Isolation and culture from the rat olfactory bulb. Methods Mol Biol 2002; 198: 41-48.

95 Riddell JS, Enriquez-Denton M, Toft A, Fairless R, Barnett SC. Olfactory ensheathing cell grafts have minimal influence on regeneration at the dorsal root entry zone following rhizotomy. Glia 2004; 47: 150-167.

$96 \mathrm{Lu} \mathrm{J}$, Feron F, Mackay-Sim A, Waite PM. Olfactory ensheathing cells promote locomotor recovery after delayed transplantation into transected spinal cord. Brain 2002; 125: 14-21.

97 Ramer LM, Au E, Richter MW, Liu J, Tetzlaff W, Roskams AJ. Peripheral olfactory ensheathing cells reduce 
scar and cavity formation and promote regeneration after spinal cord injury. J Comp Neurol 2004; 473: 1-15.

98 Feron $\mathrm{F}$ et al. Autologous olfactory ensheathing cell transplantation in human spinal cord injury. Brain 2005; 128: 2951-2960.

99 Smith PM, Lakatos A, Barnett SC, Jeffery ND, Franklin RJM. Cryopreserved cells isolated from the adult canine olfactory bulb are capable of extensive remyelination following transplantation into the adult rat CNS. Exp Neurol 2002; 176: 402-406.

100 Jeffery ND, Lakatos A, Franklin RJM. Autologous olfactory glial cell transplantation is reliable and safe in naturally-occurring canine spinal cord injury. $J$ Neurotrauma 2005; 22: 1282-1293.

101 Fawcett JW, Asher RA. The glial scar and central nervous system repair. Brain Res Bull 1999; 49: 377-391.

102 Lakatos A, Barnett SC, Franklin RJM. Olfactory ensheathing cells induce less host astrocyte response and chondroitin sulphate proteoglycan expression than Schwann cells following transplantation into adult CNS white matter. Exp Neurol 2003; 184: 237-246.

103 Raisman G. Olfactory ensheathing cells - another miracle cure for spinal cord injury? Nat Rev Neurosci 2001; 2: 369-375.

104 Kulbatski I, Mothe AJ, Nomura H, Tator CH. Endogenous and exogenous CNS derived stem/progenitor cell approaches for neurotrauma. Curr Drug Targets 2005; 6: 111-126.

105 Bradbury EJ et al. Chondroitinase ABC promotes functional recovery after spinal cord injury. Nature 2002; 416: 636-640.

106 Nikulina E, Tidwell JL, Dai HN, Bregman BS, Filbin MT. The phosphodiesterase inhibitor rolipram delivered after a spinal cord lesion promotes axonal regeneration and functional recovery. Proc Natl Acad Sci USA 2004; 101: $8786-8790$. 